Wilhelm Köller

Formen und Funktionen der Negation 



\section{Wilhelm Köller}

\section{Formen und Funktionen der Negation}

Untersuchungen zu den Erscheinungsweisen einer Sprachuniversalie 
ISBN 978-3-11-045284-6

e-ISBN (PDF) 978-3-11-045533-5

e-ISBN (EPUB) 978-3-11-045288-4

\section{Library of Congress Cataloging-in-Publication Data}

A CIP catalog record for this book has been applied for at the Library of Congress.

\section{Bibliografische Information der Deutschen Nationalbibliothek}

Die Deutsche Nationalbibliothek verzeichnet diese Publikation in der Deutschen Nationalbibliografie; detaillierte bibliografische Daten sind im Internet über http://dnb.dnb.de abrufbar.

(C) 2016 Walter de Gruyter GmbH, Berlin/Boston

Druck und Bindung: $\mathrm{CPI}$ books $\mathrm{GmbH}$, Leck

@ Gedruckt auf säurefreiem Papier

Printed in Germany

www.degruyter.com 
Jedes ausgesprochene Wort erregt den Gegensinn.

Johann Wolfgang von Goethe

Wo ist die Weisheit, die wir im Wissen verloren haben?

Wo ist das Wissen, das wir in der Information verloren haben?

T. S. Elliot

Jedes Problem wird unlösbar, wenn man es zu lange betrachtet. Erwin Chargaff

Wer alles durchschaut, sieht nichts mehr.

Clive Stapels Lewis

$\mathrm{Ja}=$ Nein. Der Unterschied liegt in der Frage.

Stanisław Jerzy Lec

Nur kleine Rätsel haben eine einzige Lösung.

Erwin Chargaff 
